Durch diese anscheinend guten Erfolge fühlte ich mich zur Nachprüfung der Methode an einer Reihe von Fällen angeregt; durch Entgegenkommen von Prof. Gram konnte ich die Arbeit im Laboratorium der Abteilung A im Rigshospital ausführen, wie auch vorzugsweise Krankenmaterial aus dieser Abteilung dabei in Anwendung kam.

In der Technik befolgte ich strikte die Anordnungen von Hermann und Perutz.

Das nötige Blut wurde einer Armvene des Patienten durch Punktur

Aus der Abteilung A des Rigshospitals in Kopenhagen.

(Vorstand: Prof. Chr. Gram.)

\section{Ueber die von Porges angegebene und von Hermann und Perutz modifizierte Syphilis- reaktion.}

Von S. A. Gammeltoft.

Die ungeheure Bedeutung der Wa.R. für die Diagnose sowohl der frischen als der latenten Syphilis ist über jeden Zweifel erhaben. Während eine positive Wa.R. als vollständig sicherer Beweis davon betrachtet werden kann, daß der betreffende Patient eine syphilitische Infektion durchgemacht hat, bedeutet, wie bekannt, eine negative Reaktion keineswegs, daß es ausgeschlossen ist, daß eine solche stattgefunden hat, indem die Reaktion in vielen Fällen von ausgesprochener Lues negativ ausfällt.

Außer der oft versagenden Reaktion bei älteren Luesfällen gibt es noch ein Moment, das der allgemeinen Verbreitung der Methode hinderlich gewesen ist, nämlich daß sie sich mit Sicherheit nur von sehr geübten Untersuchern und in großen, wohleingerichteten Laboratorien mit dazugehörigen Ställen ausführen läßt.

Es wurde deshalb auch gleich von Anfang an darauf hingearbeitet, eine Modifikation ausfindig zu machen, die einfacher wäre, ohne die Zuverlässigkeit der Methode zu beeinträchtigen.

Ferner hoffte man auch, daß es auf diesem Wege möglich sein würde, eine empfindlichere Reaktion als die Wassermannsche zu finden, die auch in denjenigen Luesfällen Reaktion ergeben würde, wo die Wa.R. versagt.

Unter den verschiedenen Verfahren, die man zu dem Ende versucht hat, haben die sog. Ausflockungsreaktionen die am meisten verheißenden Resultate geliefert, wenn diese auch bei weitem noch nicht die Zuverlässigkeit der Wa.R. erreicht haben und auch noch nicht zur Genüge durchgeprüft worden sind. Von den vielen Ausflockungsreaktionen, die angegeben worden sind, ist die von Hermann und Perutz ${ }^{1}$ ) mitgeteilte Modifikation der ursprünglichen Porgesschen Reaktion die verheißungsvollste.

Die beiden Forscher fanden bekanntlich, daß man, wenn gleiche Teile einer $2 \%$ igen Lösung von glykocholsaurem "Natrium und einer alkoholischen Cholesterinsuspension mit dem zu untersuchenden inaktivierten Serum versetzt werden, in Fällen von Lues eine Ausflockung grober Flocken erhielt, die sich schließlich als ein tatsächlicher Niederschlag am Boden absetzten, während das Serum vollständig klar blieb, wenn von keiner Lues die Rede war. Sie untersuchten im ganzen 134 Syphilisfälle; davon reagierten 108 positiv bei der glykocholsauren Natrium-Cholesterinprobe; von den 134 Fällen, wurden 82 zugleich mit glykocholsaurem Natrium allein untersucht (ursprünglich Porges. sche Reaktion), was 61 positiv und 21 negativ ergab; die kombinierte Reaktion ergab in denselben Fällen 69 positiv und 12 negativ. Nach Wasser mann wurden von ihnen 102 Sera untersucht, davon 72 positiv und 30 negativ. Die Cholesterinprobe gab 76 positiv und 26 negativ, was mit anderen Worten heißt, daß die Hermann-Perutz sche Reaktion um $4 \%$ häufiger positive Reaktion bei Luesfällen ergab als die Wa.R.

Es verdient noch hervorgehoben zu werdell, daß 8 positive $\mathrm{Her}$ mann-Perutzsche Reaktionen negativen Wassermannschen Reaktionen entsprachen, während 4 negative Perutzsche Reaktionen nach Wassermann positiv waren. Die beiden Reaktionen" entsprechen einander anscheinend nicht ganz.

Von 89 Kontrollfällen gab einer, cin Tuberkulosefall, mit der Hermann-Perutzschen Probe positive Reaktion; leider konnte, der geringen Serummenge wegen, die Wa.R. nicht angestellt werden.

1) Medizinische Klinik 1911, No. 2. entnommen. Nachdem sich Serum gebildet hatte, wurde dies in ein Zentrifugenglas getan und zentrifugiert. Dadurch erhielt man im allgemeinen ein vollständig klares Serum; ein geringer Grad von Hämolyse beein. trächtigt, wie Hermann und Perutz schon hervorhoben, die Reaktion nicht; dagegen hatte eine stärkere Hämolyse stets einen hemmenden EinfluB. Das Blut wurde gewöhnlich morgens bei nüchternem Magen entnommen, da das Serum unmittelbar nach Mahlzeiten oft durch Fett. tropfen getrübt wird. Nach der Zentrifugierung wurde das Serum durch halbstündiges Erwärmen im Wasserbad auf $55^{\circ}$ inaktiviert. Danach wurde $0,4 \mathrm{ccm}$ Serum, $0,2 \mathrm{~cm}$ einer $2 \%$ igen wäßrigen glykocholsauren Natriumlösung (Merck) und $0,2 \mathrm{ccm}$ einer Cholesterinsuspension genonmen, die aus untenstehender Stammlösung im Verhältnis $1: 19$ hergestellt war; diese Lösung hatte folgende Zusammensetzung:

$2 \mathrm{~g}$ glykocholsaures Natrium,

$0,4 \mathrm{~g}$ Cholesterin,

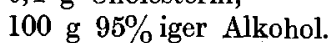

Das ganze wurde in Reagenzröhrchen abpipettiert und 20 Stunden bei Vermeidung jeder Erschütterung bei Zimmertemperatur stehen gelassen. Die Ablesung erfolgte im Gestell selbst. Nur die Fälle wurden als positiv bezeichnet, wo in den betreffenden Gläsern eine deutliche Ausflockung, entweder als starker Niederschlag oder als große, grobe Flocken in der ganzeıl Flüssigkeitssäule beobachtet wurde. "Nur deutliche Ausflockungen sind als positiv zu bezeichnen ", darauf ist besonderes Gewicht zu legen, und hier haben wir das Hauptsächliche der Reaktion. Wenn man diese Regel beachtet, wird man, meines Erachtens, nach ein paar Mal angestellter Reaktion, nur selten über den Ausfall der Reaktion im Zweifel sein. - Durch dieses Verfahren gelangte ich zu einem in allen Beziehungen befriedigenden und ermutigenden Resultat.

Im ganzen habe ich die Reaktion etwa $200 \mathrm{mal}$ angestellt, jedoch in einzelnen Fällen bis drei- bis viermal mit Unterbrechung mit dem Serum desselben Patienten; die Gesamtanzahl untersuchter Patienten beträgt 156. Das Resultat der Untersuchung ist aus untenstehender Tabelle ersichtlich. Von diesen Fällen bedürfen die in den drei ersten Zeilen angeführten keiner näheren Erklärung; es fand sich unter den 84 Fällen negativer Wassermannscher und Hermann-Perutzscher Reaktion eine Fülle von allen möglichen inneren Krankheiten, sowohl febrilen als afebrilen, außerdem einige Fälle von Tabes dorsalis und anderen Nervenleiden; in keinem dieser Fälle kam bei der Hermann-Perutzschen Reaktion Ausflockung vor.

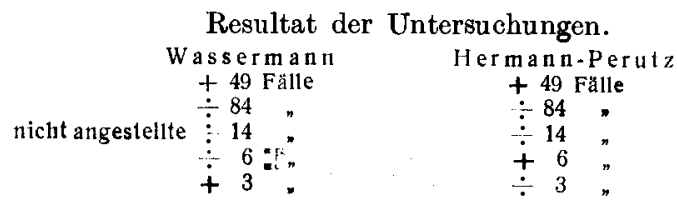

i In den 14 Fällen, wo keine Wa.R. angestellt wurde, ergab weder die Anamnese noch die objektive Untersuchung ein Anzeichen von Syphilis, und da die Hermann-Perutzsche Reaktion in allen diesen Fällen negativ war, begnügte ich mich mit dieser.

Die Fälle, wo die beiden Reaktionen nicht übereinstimmen, sind die interessantesten, und wir wollen sie deshalb etwas genauer betrachten.

Im ganzen liegen sechs Fälle von Wassermann negativ und Hermann-Perutz positiv vor.

Im ersten dieser Fälle handelte es sich um einen Patienten mit Lues in der Anamnese; früher behandelt. Dieser Fall empfiehlt also die Reaktion.

Im Falle No. 2 handelte es sich um ein junges Mädchen von einigen zwanzig_Jahren, die wegen Morbus cordis und Hämoptysis behandelt wurde. Sie hatte früher an einer Keratitis interstitialis gelitten und war deswegen mit Schmierkuren und Jodkali behandelt worden; außerdem hatte sie eine Andeutung von Hutchinsonschen Schlleidezähnell; ihre Eltern hatten zu Anfang der Ehe sechs totgeborene Kinder, und es wurde festgestellt, da $B$ ihnen seinerzeit die Ehe abgeraten worden war. Daß es sich hier um einen Fall von kongenitaler Syphilis handelte, unterliegt wohl keinem Zweifel. 
Im Falle No. 3 versagte, soweit ersichtlich, die HermannPerutzsche Reaktion. Patient war ein etwa 45jähriger Mann, der Symptome eines ernsthaften Leidens der Galleuwege darbot. Er hatte einen sehr starken Ikterus; da dieser bei interner Behandlung nicht schwand, wurde er in eine chirurgische Privatklinik transferiert. Hier fand explorative Laparotonie statt, und es zeigte sich wun, daß aller Wahrscheinlichkeit nach ein Cancer vorlag; es fanden sich Knotell in der Leber; es wurde deshalb nichts unternominen. Patient starb kurz darauf. Es fand keine Sektion statt. Weder die Anamnese noch die objektive Untersuchung führte zu einen Luessymptom; die Herunann-Perutzsche Reaktion hat" also in diesem Falle fehlgeschlagen.

Der Fall No. 4 war eine Tabes dorsalis incipiens; Wa.R. negativ, Hermann. Perutz, wenn auch nur schwach, so doch deutlich positiv.

Der Fall No. 5 war ein Mann, der wegen einer Fractura femoris dextri in der Chirurgischen Abteilung des Krankenhauses untergebracht worden war. Der Bruch war beim Stiefelanziehen entstanden; Patient hatte dabei plötzlich einen lauten Knall gehört und darauf gemerkt, daß er das Bein weder bewegen, hochheben, noch darauf sich stützen konnte. Apßer dem erwähnten Bruch mitten am Oberschenkel wies Patient folgende Abnormitäten auf: seine Pupillen waren nicht ganz rund und reagierten nicht auf Licht; es fanden sich keine Patellarreflexe. Er stellte Syphilis in Abrede, gab aber $\mathrm{zu}$, mehrmals an Urethritis gelitten zu haben. Der Fall ist, wie man sieht, in hohem Grade verdächtig und ähnelt am meisten einer Tabes dorsalis incipiens. Auch in diesem Falle war Wa.R. negativ und Hermann. Perutz positiv, wenn auch nicht besonders stark.

Der Fall No. 6 ist eigentlich der interessanteste von allen. Eer betrifft eine 67jährige Frau, die am 19. Oktober 1911 mit der Diagnose Anaemia gravis, Tumor lienis in der Abteilung A untergebracht wurde; aus dem Journal und später eingeholten Nachrichten geht hervor, daß Patientin früher immer gesund war, bis vor einigen Monaten, da gegenwärtiges Leiden einsetzte; es äußerte sich zunächst als starke Müdigkeit und Herz-

klopfen. Die Frau hatte sechsmal geboren und einmal zwischen der zweiten und dritten Geburt abortiert. Ihr Gatte war vor Jahren in einem Spital für Lungentuberkulose an Tuberculosis pulmonalis gestorben; es hat keine Sektion stattgefunden, und das Journal sagt nichts von Lues. Er war ein Potator. Der eine Hoden enthielt einen kleinen Knoten; vielleicht war dieser tuberkulöser Art. Patientin stellte Genitalaffektionen in Abrede und hat nie Hauteruptionen gehabt.

Die objektive Untersuchung ergab eine vergrößerte Milz, Achylie, $30 \%$ Hämoglobin, normale Leukozytenanzahl; trotz wiederholter Untersuchungen nie Blut in den Faeces. Patientin wurde darauf, wie vordem zu Hause, bis zum 6. Dezember mit Arsenikpräparaten behandelt Das Hämoglobin blieb während dieser Behandlung vollständig unverändert, schwankte zwischen 22 und 30 ; bereits am 9 . November war sowohl Perutzsche Reaktion als auch die Wa.R. angestellt worden; erstere war sehr kräftig positiv, letztere negativ; beide Untersuchungen wurden mehrmals wiederholt. Am 9. Dezember bekam Patientin erst Jodeisenpillen und einige Tage später Mixt. jod. hydr. rubri. Bei dieser Behandlung besserte sich der Zustand, und das Hämoglobin steigerte sich bis auf 50 . Indessen vertrug Patientin die Arznei schlecht, und man mußte einige Zeit damit aufhören. Später bekam sie Sublimatpillen, und die Hämoglobinmenge nahm wieder zu, sodaß sie am 28. Februar $191262 \%$ betrug; Anzahl der roten Blutkörperchen 4400000 . Die Kranke befindet sich subjektiv viel besser; gleichzeitig hat die Perutz sche Reaktion an Stärke abgenommen und war am 25. Februar fast ganz versehwunden.

Dieser Fall ist interessant, weil man hier mittels der HermannPerutzschen Reaktion imstande gewesen ist, die Behandlung anzuwenden, die anscheinend die einzige effektive war. $\mathrm{Da}$ nach Boas Arsenik die Wa.R. hindert, ist es ja nöglich, daß hier der Grund dazu liegt, daß sie negativ war, aber um so wertvoller muß es in dem Falle sein, daß dies bei der Hermann - Perutzschen Reaktion nicht zu geschehen scheint.

Von den drei restlichen Fällen, bei denen das Verhältnis umgekehrt war, war der eine ein Fall von Tabes dorsalis incipiens: Wa.R. schwach, Her mann - Perutz negativ.

Die beiden anderen waren Luesfälle: Wa. R. $0-60-100$ und 0-30-100; Hermann-Perutz in beiden Fällen negativ; zum Vergleich mag dienen, daß in einem anderen Luesfalle einer Wa.R. von 0-30-100 eine deutliche Hermann - Perutzsche Reaktion entsprach.

Der Gesamteindruck der oben angeführten Resultate ist befriedigend und fordert $\mathbf{z u}$ einer weiteren Vertiefung der Methode auf; es ist natürlich unmöglich, sich auf Grund eines so geringen Materials über die Zukunft der Methode zu äußern. Ein Mangel des vorliegenden Materials ist die verhältnismäßig geringe Anzahl positiver Fälle; indessen ist es ja auch nicht zum wenigsten;, von Interesse festzustellen, ob die Reaktion auch bei anderen Erkrankungen positiv ausfällt, und hier dürften meine Untersuchungen von O'einigem Wert sein. Außer in dem einen Falle von Cancer hepatis wurde keine sichere positive Hermann-Perutzsche Reaktion festgestellt in Fällen, wo nicht mit großer Wahrscheinlichkeit von Syphilis die Rede war.

Die Methode muß jedoch weit gründlicher durchgeprüft werden, bevor sich ein Urteil fällen läßt.

Abgesehen von dem großen theoretischen Interesse, wird diese Reaktion stets eine Bedeutung haben, indem sie ein leich tes Mittel abgibt, um bei eklatanter Lues die Wirkungen einer etwaigen Kur zu kontrollieren.

Wer einigemal die Gelegenheit hatte, eine kräftige positive Reaktion zu beobachten und zu sehen, wie sich die großen, groben Flocken allmählich bilden und sichtbar werden, gibt nicht leicht die Hoffnung auf die Brauch barkeit und die biologische Bedeutung dieser Reaktion auf. Es ist klar, daß diese Reaktion, wie jedes andere Problem, die Wa.R. nicht ausgeschlossen, ihre Kinderkrankheiten durchzumachen haben wird und vielleicht in mehreren Bezieh ungen modifiziert werden muß, bevor sie den an sie gestellten Ansprïchen entspricht und für die Syphilisdiagnose eine tatsächliche Bedeutung erhält, und zwar kaum als Antagonistin der Wa.R., sondern vielmehr als notwendige und fördernde Ergänzung.

Zusammenfassung. Die Hermann-Perutzsche Syphilisreaktion, die eine Modifikation der Porgesschen Reaktion ausmacht, gibt bei allen Fällen von Lues ebenso gute Resultate wie die Wa.R.; die beiden Reaktionen decken einander abel nicht ganz. Bei einer Untersuchung an im ganzen 156 Fällen kam nur einnal, und zwar bei einem Cancer hepatis, eine positive Hermann-Perutzsche Reaktion vor, wo weder anamnestisch noch klinisch Luessymptome vorlagen und wo die Wa.R. negativ war. Als bequemes und schnelles Mittel, um bei Syphilisfällen die etwaige Wirkung einer Kur verfolgen zu können, wird diè Methode große Bedeutung haben. 